\title{
Nursing care for adolescents with graft versus host disease after allogeneic hematopoietic stem cell transplantation
}

\author{
Anastasia A. Kraeva, Irina A. Badanova, Lubov A. Shepeleva, Maria U. Averyanova, Svetlana I. Gortinskaya-Oleschko, \\ Ludmila S. Zubarovskaya, Boris V. Afanasyev \\ Raisa Gorbacheva Memorial Research Institute for Children Oncology, Hematology and Transplantology, The First St. Peters- \\ burg I.Pavlov State Medical University, Russia \\ Contact: Anastasia A.Kraeva \\ E-mail: irulkina_pochta@mail.ru
}

\section{Background}

Graft versus host disease (GVHD) is a common severe complication after allogeneic hematopoietic stem cell transplantation (allo-SCT). Management of GVHD is based on multidisciplinary approach. In particular, nursing care and psychological support play an important role, especially, in children and adolescent patients. The aim of our study was to define incidence of acute and chronic GVHD in teenagers undergoing allo-SCT and to assess a role of nursing for the treatment process, patient care and psychological support.

\section{Patients and Methods}

The data were collected from 87 recipients of allo-SCT with acute and chronic GVHD. All the patients suffered from oncohematological disorders. Age of patients varied from 14 to 20 years.

\section{Results}

Frequency of acute GVHD was 59\% $(n=51)$, and incidence of chronic GVHD was $14 \%(n=12)$. Both types of GVHD, acute and chronic, were observed in $27 \%(n=24)$. Involvement of skin and mucous membranes was observed in $49 \%$ $(n=43)$, affection of gastrointestinal tract was revealed in $31 \%(n=27)$, liver was involved in $19.5 \%(n=17)$. Incidence of GVHD after unrelated HLA-matched allo-SCT was
67\% ( $\mathrm{n}=58)$, after haploidentical allo-SCT, the incidence of GVHD was $18 \%(n=15)$, and only $15 \%(n=13)$ after related HLA-matched allo-SCT. All the patients also filled a questionnaire depicting quality of life (QoL). Up to $65 \%$ teenagers with GVHD had psychological problems (depression, misbehavior, abnormal communication with relatives and others). Most of these problems were directly induced by GVHD or by GVHD-associated limitations. QoL was also influenced by long-lasting steroid therapy, prolonged duration of hospitalization and problems in communication with counterparts. We developed recommendations for GVHD patients and their relatives on regime and care. Introduction of these recommendations improved management of patients with GVHD.

\section{Conclusion}

Clinical nurses should be aware of GVHD and associated problems in teenagers after allo-SCT. Patients with GVHD require high professional level of nursing (including psychological support for patients and relatives). Development of universal recommendations for patient care after allo-SCT will significantly improve the quality of treatment.

\section{Keywords}

Graft-versus-host disease, adolescents, incidence, quality of life, nursing care. 


\title{
Сестринский уход для подростков с реакцией «трансплантат против хозяина» после аллогенной трансплантации гемопоэтических стволовых клеток
}

\author{
Анастасия А. Краева, Ирина А. Баданова, Любовь А. Шепелева, Мария Ю. Аверьянова, Светлана И. Гортинская-Олеш- \\ ко, Людмила С.Зубаровская, Борис В. Афанасьев
}

НИИ детской онкологии, гематологии и трансплантологии им. Р.М. Горбачевой, Первый Санкт-Петербургский Государственный Медицинский Университет им. И.П. Павлова, Санкт-Петербург, Россия

\section{Введение}

Реакция «трансплантат против хозяина» (РТПХ) является частым тяжелым осложнением после аллогенной трансплантации гемопоэтических стволовых клеток (алло-ТГСК). Лечение и контроль РТПХ основаны на мультидисциплинарном подходе. В частности, сестринский уход и психологическая поддержка играют важную роль, особенно у больных детей и подростков. Целью нашего исследования было определение встречаемости острой и хронической РТПХ среди подростков, прошедших ТГСК и оценка роли сестринского ухода в лечебном процессе, уходе за больным и психологической поддержке.

\section{Пациенты и методы}

Были собраны данные о 87 реципиентах алло-ТГСК с острой и/или хронической РТПХ. Все пациенты первично имели онкогематологические заболевания. Возраст пациентов варьировал от 14 до 20 лет. Результаты. Частота острой РТПХ в этой группе составляла 59\% $(\mathrm{n}=51)$, а встречаемость хронической РТПХ была $14 \%$ $(\mathrm{n}=12)$. Оба типа РТПХ (острая и хроническая) наблюдались в $27 \%$ случаев $(\mathrm{n}=24)$. Поражения кожи и слизистых отмечались у 49\% больных (n=43), патология желудочно-кишечного тракта выявлялась в $31 \%$ случаев $(\mathrm{n}=27)$, печени - в $19.5 \%(\mathrm{n}=17)$. Частота РТПХ после неродственной HLA-совместимой алло-ТГСК была 67\% $(\mathrm{n}=58)$, после гаплоидентичной ТГСК - 18\% ( $\mathrm{n}=15)$, и только 15\% (n=13) после родственной HLA-совместимой алло-ТГСК. Все пациенты также заполняли вопросник, результаты которого отражают качество жизни (КЖ). До 65\% больных подростков имели психологические проблемы (депрессию, изменения поведения, нарушения отношений с родственниками и окружающими). Большинство этих проблем было прямо связано с РТПХ или связанными с ней ограничениями. На качество жизни влияли также: длительная стероидная терапия, пролонгированное пребывание в больнице и проблемы общения с окружающими. Мы разработали рекомендации для пациентов с РТПХ и их родственников по режиму и уходу. Внедрение этих рекомендаций улучшило лечение и уход за больными с РТПХ.

\section{Заключение}

Медицинские сестры должны быть в курсе особенностей РТПХ, и связанных с этим проблем, возникающих у подростков после алло-ТГСК. Пациенты с РТПХ нуждаются в высокопрофессиональном сестринском уходе (включая и психологическую поддержку больных и родственников). Разработка универсальных рекомендаций по уходу за больными после алло-ТГСК значительно улучшит качество лечения.

\section{Ключевые слова}

Реакция «трансплантат против хозяина», частота, подростки, качество жизни, сестринский уход. 